\title{
Differentiation of the Age-Crime Curve Trajectory by Types of Crime
}

\author{
Roberto Flores De Apodaca', Abigail M. Csik, Erica K. Odell, Jason R. O'Brien \\ Erin R. Morris, Christopher W. Thorne \\ Psychology Department, Concordia University, Irvine, California
}

\begin{abstract}
The observed relationship between age and criminal behavior in the general population is widely regarded as one of the more venerable findings in the field of criminology (Fagan \& Western, 2005; Sweeten, Steinberg \& Piquero, 2013). This phenomenon, in which crime rates have been consistently observed to rise through adolescence, peak in the mid to late 20's and decline steadily with age, has been routinely referred to as the Age-Crime Curve (ACC). While this broad correspondence between age and crime has been widely observed, the particular sub-components and co-variants of this relationship are less well understood and have come under increasing investigation (Pratt \& Cullen, 2005). The current study continued in this progression by examining the ACC arrest trajectories of various property versus violent crimes, as well as the relative pattern of specific crimes within those broad, categorical trajectories using state-wide arrest data, over the course of 7 years (2007-2013) compiled by the California State Department of Justice (CSDOJ). Our most fundamental finding was that Property and Violent crimes, in toto, conformed to the classic description of the ACC. Chi-Square analyses showed that Burglary and Robbery showed significantly different trajectories from their Property and Violent counterparts, respectively. Burglary arrests actually go down from the $<20$ category to the $20-29$ age category. Although not as dramatically steep as Burglary, Robbery also showed a decline from the earliest $(<20)$ to the next category (20-39). These findings challenge the invariance hypothesis of the ACC. Future researchers may want to include all forms of arrests in investigating ACC trajectories as well as analyze the data with different categorizations of age, or with no age categorizations at all; examining more nuanced relationships between aging and criminal conduct.
\end{abstract}

Keywords: Age-Crime Curve Differentiation

\section{Differentiation of the Age-Crime Curve Trajectory by TyPeS of Crime}

The observed relationship between age and criminal behavior in the general population is widely regarded as one of the more venerable findings in the field of criminology (Fagan \& Western, 2005; Sweeten, Steinberg \& Piquero, 2013). This phenomenon, in which crime rates have been consistently observed to rise through adolescence, peak in the mid to late 20's and decline steadily with age, has been routinely referred to as the Age-Crime Curve (ACC). While this broad correspondence between age and crime has been widely observed, the particular sub-components and co-variants of this relationship are less well understood and have come under increasing investigation (Pratt \& Cullen, 2005). Work on the ACC has progressed from theorizing about its origins, to demonstrating its existence empirically, and most recently, to a growing, empirical understanding of the intricacies within the overall ACC phenomenon (Shulman, Steinberg \& Piquero, 2013). The current study continued in this progression by examining the ACC arrest trajectories of various property versus violent crimes, as well as the relative pattern of specific crimes within those broad, categorical trajectories for an entire state's arrest data, over the course of seven years.

\section{MAJOR THEORIES EXPLICATING THE ACC}

The first universally regarded theory on the causes of the ACC was proposed by Hirschi and Gottfredson (1983). They argued that a number of theses undergirded the observed ACC phenomenon; 1) that its trajectory was invariant across social and cultural conditions, 2) that it could not otherwise be accounted for by any variable or combination of variables available to criminology, and 3) that the causes and correlates of criminality are the same in every age. They concluded that the relationship between age and crime was "sufficiently invariant over a broad range of social conditions" that it was a unitary, significant and invariant determinant of criminal behavior over time. Their

${ }^{1}$ Corresponding Author: drflores@socal.rr.com 
American Research Journal of Humanities and Social Sciences, Volume 1, Issue 4, 2015 ISSN 2378-7031

theoretical arguments were furthered by explanations emphasizing biological and evolutionary constructs (Kanazawa \& Still, 2000), such as testosterone levels and development of the prefrontal cortex.

Several macro-level theories emphasizing social factors for the ACC have been proposed. Pratt and Cullen (2005) surveyed these theories and found that social disorganization and resource deprivation were among the strongest arguments explaining the ACC. Young people are less involved in social institutions that dampen involvement in criminality; e.g. full time employment, marriage and parenting. They noted that various theorists had proposed that structural conditions or deprivation in the lives of individuals "lead to higher levels of social disorganization." In addition to these theories, delinquency during adolescence is often seen as a "rite of passage" (Fagan \& Western, 2005), which sets the groundwork for subsequent criminality.

Tittle and Grasmick (1997) complemented Hirschi and Gottfredson's (1983) theories by further suggesting that the ACC is invariant, inexplicable with social science variables, and involves no interaction with any other variable that explains or correlates with crime.

Tittle and Grasmick (1997) tested the effects of 10 explanatory variables that are commonly hypothesized to contribute to the ACC. They found that the inter-correlation between these variables "explained at least $40 \%$ and perhaps $60 \%$ of the associations, in the sense of reducing them below significance by controlling all of the explanatory variables." The ACC phenomenon was so empirically robust that they were not "able to reduce the agecrime association by even as much as $35 \%$ " across all explanatory variables, even when using them simultaneously (Tittle \& Grasmick, 1997). While concluding that the invariant aspect of the theory held up, the inexplicability and non-interactive theories produced ambiguous results.

Sweeten, Steinberg \& Piquero (2013) further explored the inexplicable and non-interaction hypotheses through a longitudinal study of over 1,300 youthful offenders. They found that "assessed separately, these [psychological and sociological] perspectives explain anywhere from $3 \%$ (procedural justice) to $49 \%$ (social learning) of the age-crime relationship. Together, changes in these constructs explained 69\% of the drop in crime from ages 15 to 25" (Sweeten et al., 2013). They concluded that while the direct relationship between age and crime persists, it can also be further explained by a number of co-occurring developmental factors.

A number of other developmental considerations have been offered as further explications of the ACC phenomenon. Fagan and Western (2005) pointed out that most violent crime drops by age twenty five. This desistance from crime usually only occurs when there has been a smooth transition into adulthood and its corresponding responsibilities. Within individuals, criminal activity tends to follow a common pattern: the individual starts with less serious crimes and commit more serious violent crimes subsequently. Individual age-crime curves may therefore follow a different trajectory than the general one established by the ACC.

The consideration of such individual factors led to the observation that the "type of offending behavior being considered, the gender of the population, and the perpetrator's exposure to the criminal justice system contribute to the variability in the curve" (Fagan \& Western, 2005). Other strong and stable correlates of crime in the general population include "strength of noneconomic institutions, unemployment, firearms ownership, percent nonwhite, and the effect of incarceration" (Fagan \& Western, 2005). These later studies challenged the invariance of the ACC posited by Hirschi and Gottfredson (1983) and ushered a generation of empirical studies into the factors mediating the ACC trajectory.

It thus appears that while the macro ACC trajectory has a well established configuration, it is not invariant across individuals, even at a macro level. A host of psychological and demographic variables have been found to affect its specific expression at the micro, individual level. It is therefore warranted to investigate if some of these variables affect group data in a comparable way.

\section{Mediators of THE ACC}

Investigations of the ACC have progressed from a global examination of its trajectory to a more nuanced and articulated understanding of the underlying specifics of this relationship (Pratt \& Cullen, 2005). A number of investigators have noted the interrelationship between environmental factors and the ACC. For example, Anderson, Bushman, \& Groom (1997) found a positive relationship between the prevalence of violent crimes and hotter years, specifically, in serious and deadly assaults. However, property crime was unaffected by temperature.

Other investigations examined the relationship of certain environmental factors on school shootings (Anderson, Bushman, \& Groom, 1997). The size of a school's population, urban or suburban location, and predominantly nonwhite enrollment were positively associated with fatal shootings (Flores de Apodaca, Brighton, Perkins, Jackson \& 
Steege, 2012). Larger, inner-city high schools with a higher proportion of non-white students were found to have a greater incidence of gun fatalities. In this same study, universities and colleges were disproportionately associated with random shootings, while high school shootings were more often characterized by targeted victims.

Socio-Economic-Status (SES) has yielded inconsistent findings in its relationship to the ACC. Fabio, Tu, Loeber, \& Cohen (2011) found in a cross-sectional study that the ACC for boys in advantaged neighborhoods was significantly different than that of boys in disadvantaged neighborhoods. Higher levels of neighborhood disadvantage were shown to be associated with increased participation in violent acts, at younger ages, over a longer range of ages. However, Shulman, Steinberg, \& Piquero (2013) found that the age-crime curve was constant across varying economic statuses, with crime peaking in adolescence. Their research findings opposed the notion that the shape of the ACC is so because younger people tend to be poorer ${ }_{2}$ and poorer people tend to commit more crime. It would appear that relationship of SES and crime is complex and multivariate, awaiting further studies into its relationship to the ACC.

One of the more often studied mediators of the ACC at the micro-level is the psychological state of the criminals. Giordano, Cernkovich, and Rudolph (2002) discussed social control theory, which states that life factors such as a close marital bond or maintaining a stable job are correlated to crime. Cognitive and identity transformations lead individuals to envision themselves as greater than their previous self and transform their deviant behavior or lifestyle.

Another example of this line of work is found in the research of Shulman, Cauffman, Piquero, and Fagan (2011). They found that moral disengagement was correlated with and predictive of juvenile offending. They observed that a decline in moral disengagement may contribute to a decrease in offenses over time, providing an internal explication for the ACC phenomenon.

Cognitive abilities, temperament, personality traits, and childhood behaviors have also been found to be consistent correlates of crime. Sampson and Laub (2005) utilized thirteen measures of cognitive abilities taken from multiple sources, in a longitudinal study of 500 men over a period of 63 years. They found that while personality traits were not strongly correlated with criminality, crime is more likely to occur when an individual's bond to society is attenuated.

Gender has also been found to play a mediating role in the expression of the ACC (Silvestri, Dowey \& Heidensohn, 2008). Studies have shown consistently that males commit more crimes than females, while their trajectories across the age spectrum are similar. In general, women commit fewer crimes and their crimes tend to be less violent than those of males (Silvestri et. al., 2008). In addition to this, males offend at an earlier age, offend more consistently, and desist offending later than females (D’Unger, Land \& McCall, 2002). Males and females also differ on "overall levels of offending, age at the onset offending, peak ages of offending, rates of police contact or arrest, and types of offences across different developmental stages" (D'Unger, et al., 2009). Broidy and Agnew (1997) found that specifically, social and psychological strain on males are "more conducive to serious violent and property crimes" whereas strains on females are "conducive to family violence."

Emotional response to stress also has an impact on criminal activity. Female expressions of anger are often "accompanied by depression, guilt, anxiety, and related states," reducing confrontation and increasing selfdestructive behavior (Broidy \& Agnew, 1997). Gender differences in criminal behavior can also be attributed to differences in "social support, opportunities, social control, and the disposition to engage in crime" (Broidy \& Agnew, 1997).

Ethnicity has also been shown to be an important mediator of the ACC. Howell and Hutto (2012) found that White males were more likely to be given probation for their crimes than other minorities, "after controlling for a variety of legal and extra-legal predictors of sentencing, race significantly impacted the likelihood of being sentenced to jail" (Howell \& Hutto, 2012). As for adult offenders Hispanic and African American offenders are more likely to be sentenced to jail than White adults, and have a more extensive record with more serious crimes. However, out of the two groups of African Americans and Hispanic offenders, African American offenders have served lengthier amounts of time in jail for their crimes.

Le and Stockdale (2011) found that Hispanic offenders were ranked most likely to commit crimes and receive punishment. Using two databases, their sample was taken from the National Longitudinal Study of Adolescent Health (Add Health) and Youth (NLSY97). Both samples involved ethnicities of White, African-American, Hispanic and Asian adolescent males, ages 13 to 25. Le and Sotckdale (2011) noted that out of the four groups of juvenile offenders they examined: "Hispanics had the highest initial rate of delinquency at age 13 (2.41 incidents), 
followed by African Americans, Asians and Whites." Loeber, Farrington \& Petechuk (2013) found that AfricanAmerican males peak earlier within the ACC than females and White males. According to the 1998 Juvenile Defendants in Criminal Courts (JDCC) convicted offenders in a sample of 3,889 offenders totaled to 56\% African American, 25\% Hispanic, and 19\% White offenders.

Howell and Hutto (2012) found that, "Compared with White youths, Black and Hispanic juveniles were significantly more apt to be sentenced to prison instead of jail and jail instead of probation, while White offenders (compared with Black offenders and Hispanic youths) were more apt to be sentenced to probation instead of incarceration." These differential rates of sentencing cannot but have an effect on the overall ACC for these different, ethnic groups.

Notable among these investigators have been those examining differences in trajectories between property versus violence crimes; i.e. those committed for personal gain versus those committed, perhaps more spontaneously, in an expression of aggression against others (Sampson \& Laub, 2003). What remains to be examined at this time is a more detailed examination of how particular property and violent crimes may be differentially associated with the ACC phenomenon.

Sampson and Laub (2003) noted that property crimes tended to peak earlier in the age spectrum while violent crimes peaked in the mid-20's. In this same study, they found that drug/alcohol related crimes showed their peak involvement in the mid-30. They argued that the types of opportunities available for crime interacts with age, and that some types of crimes are more available to older age groups; for example, fraud, which is more apt to be committed by someone who has an opportunity for credit and can engage in forgery, embezzlement, etc.

\section{Property Vs. Violent Crimes}

Property acquisitions and violent crimes follow similar, but somewhat varying age-crime relationships. McCall (2013) pointed out that, "age dependence of criminal offending have noted variations in trajectories over the life course suggesting that the aggregated age-crime curve masks significant differences in individual offense patterns."

Anderson and Felson (2012) noted that property crime tends to begin at an earlier age than violent crimes. They are the most numerous types of crimes, possibly because property crimes tend to be co-offending crime and not a solo crime. Co-offending refers to "offenses that are committed with the simultaneous presence of more than one offender." Along with co-offending, it is common for property crimes to be much more violent than violent crimes and frequent, than violent crimes.

Property crimes tend to rise in the population where: "individuals with weak social bonds, [they] are less likely to conform to normative behaviors than individuals with strong social bonds" (McCall 2013). When a neighborhood does not promote social engagement for the adolescents, they are more likely to engage in non-normative, destructive engagements, like gangs. Because of this, the "trend over the age range is of particular interest. Rather than a steady decrease in the two values as offenders age, percent co-offending and the average number of offenders increase until the age of 20 and then decrease" (Anderson \& Felson 2012). Thus, property crimes, in total, have an earlier peak and a longer duration of offending. Co-offending appears to be a confounding variable in this scheme.

On the other hand, violent crimes tend to have a later start, and shorter duration. McCall (2013) found that: "characteristics of youths who are less engaged in mainstream schooling and work institution and thus [creates a] greater risk of involvement in serious violent crimes." According to McCall's (2013) Differential Institutional Engagement Hypothesis: "cities with greater levels of disengaged youth have a negative impact on the structurehomicide relationship, resulting in a positive increase of delinquent behaviors." Offenders of violent crimes peak later and have a shorter duration of time while actively offending. As important as it is to look at all trajectories during childhood to determine which children are at risk, it appears that of all the mediators, the most important one appears to be age (Godfrey \& Schulman, 1972).

Loeber, Farrington, \& Petechuck (2013) support the notion that only a small percentage of delinquent children become lifetime offenders. They often stop offending in late adolescence or early adulthood; a time marked by an increase in self-control and decrease in impulsive behavior. Differing trajectories do exist for subpopulations, however. The curve for violence peaks later than the curve for property (Sampson \& Laub, 2003), while the curve for females peaks earlier than the curve for males (Fagan \& Westen, 2005).

What remains to be further articulated is: are there specific property or violent crimes that themselves differ from the general ACC? 


\section{METHOD}

\subsection{Data Source}

Our data were gleaned from the archives made publicly available by the State of California Department of JusticeOffice of the Attorney General (CSDOJ). We examined total arrest data (not convictions or self-reports), for the seven years between 2007 and 2013 (the most recent years for which all arrest data were available). These were available in tabular form, found on-site. As noted above, there is considerable support in the literature for arrests, rather than convictions or self-report, as the most valid proxies for the (unknowable) total number of crimes committed (Kirk, 2006).

\subsection{Arrests, Convictions, Self-Reports}

There have been two main approaches for gathering data on the ACC which have yielded somewhat differing base rates: self-reports and archival data. Kirk (2006) found that "participation and frequency of crime are higher in selfreport data than in the official data, except for black youth, and the average age of onset is lower in the self-report data." This stands to reason, as it is not expected that someone will be arrested every time they commit a crime. Archival (i.e. arrest or conviction) data are assumed to always yield an underestimate (if not more objective) index of crime prevalence rates. Because of this, Kirk (2006) concluded that: "it is questionable whether self-reports and official data will produce similar conclusions about the prevalence and incidence of arrest." While it was found that there is greater continuity of official arrest data in the age-crime curve with archival than self-report data, both methods have shown a similar peak (archival later than self-report) of crime in late adolescence and a decline thereafter.

Self-report methodology has the empirical advantage of collecting specific information on individuals, not provided by official data. However, through self reports, there is often both over and underreporting of crime to an unknown degree when compared to arrest records. Official arrests record the arrests in a specific point in time and there are no self-report, biasing factors. For example, the more crime one has committed, the less they tend to remember (and report) of each crime (Kirk, 2006). This confound is not at work in official arrests. Still archival data have their own sources of inaccuracies. The accuracy of official arrest data varies by crime type (e.g. victimization crime types rely on reporting and are disproportionately reported). In addition, many crimes do not lead to arrest (Kirk, 2006).

While self-report studies are cross-sectional in essence, objective official arrest records that follow the life of individuals (i.e. longitudinal), giving a more direct, accurate depiction of the ACC phenomenon. When self-report studies are longitudinal, attrition rates are often high, due to a host of factors, including current involvement in crime (Brame \& Piquero, 2003). These researchers found that as the study progressed, there was, "both a decline in serious delinquency as well as a decline in participants of the study." Because of this, the ACC is not captured as validly as it would under a theoretical ideal.

It is clear that neither methodology is ideal, and that each has expected sources of confounds. Estimates of crime garnered through self-reports tend to overestimate crime when compared with actual crime statistics (Kirk, 2006). However, it is better to have a stable underestimation of crime (found in official arrest data) than an unstable underand over-estimation of crime (provided in self-reports). For this study, we chose to examine official arrest data provided by the California State Department of Justice for the seven years between 2007 and 2013. These archival sources provided the official statistics of all arrests conducted in the state during those years, by the specific crimes the arrests were charged with (at least initially).

\subsection{Age Categorization}

The range of ages chosen for this study were those set in the data sets published by the CSDOJ. All crimes committed by individuals under the age of 20 were combined after considering the number of crimes committed per age group. Relatively few crimes were committed by individuals under 10, therefore the age range under 10 was combined with the age range 10-20 to make the data more meaningful categorization. The remaining age ranges, were those provided by the SCDOJ, as follows: <20, 20-29, 30-39, 40-69 and >70.

\subsection{Property Crimes}

We defined property crime as crimes of acquisition where the procuring of money or property is the object and underlying motivation for the crime. The specific property crimes we investigated were: burglary, theft, motor vehicle theft, and forgery as property crimes. 
American Research Journal of Humanities and Social Sciences, Volume 1, Issue 4, 2015

ISSN 2378-7031

The SCDOJ's definitions for the property crimes we examined are as follows:

Burglary: the unlawful entry of a structure to commit a felony or a theft. Attempted burglary is included.

Grand Theft: the unlawful taking of someone else's property when it is valued at more

han nine hundred fifty dollars (\$950)

Motor Vehicle Theft: The theft or attempted theft of a motor vehicle.

Forgery: Signing someone else's name, faking someone else's handwriting, changing or falsifying any document for your own benefit and gain.

\subsection{Violent Crimes}

We used the definition of violence inherent in the most frequently used instrument for assessing the risk of violence in an individual; the HCR-20. This instrument defines violence as the deliberate actual, attempted, or threatened physical harm to a non-consenting recipient (Douglas, Hart \& Webster, 2013). We investigated the specific crimes of homicide, forcible rape, robbery, assault, and kidnapping as these offer robust enough numbers for statistical analyses and are equally violent in nature. They are defined by the SCDOJ as follows.

Homicide: the willful (non-negligent) killing of one human being by another. Murder and non-negligent manslaughter are included.

Forcible Rape: the carnal knowledge of a female forcibly and against her will. Assaults or attempts to commit rape by force or threat of force are included.

Robbery: the taking or attempting to take anything of value from the care, custody, or control of a person or persons by force or threat of force or violence and/or by putting the victim in fear.

Assault: an unlawful attack by one person upon another for the purpose of inflicting $\quad$ severe $\quad$ or aggravated bodily injury. This type of assault usually is accompanied by the use of a weapon or by means likely to produce death or great bodily harm.

Kidnapping: occurs when a person, without lawful authority, physically moves another person without that other person's consent, with the intent to use that abduction for another, nefarious objective.

\section{RESULTS}

The arrest data in California for the years 2007-2013 were combined and grouped into the age categories described above. They were then subjected to a series of Chi-Square analyses aimed at detecting potential differences in the proportional representation of the independent variables (i.e. property and violence-related crimes) across the different age brackets.

The results are presented in figures and tables, in the following three sections; first, the total number of property and violence arrests. The second section examines the four different property crimes, and the third section analyzes the five, separate violent crimes.

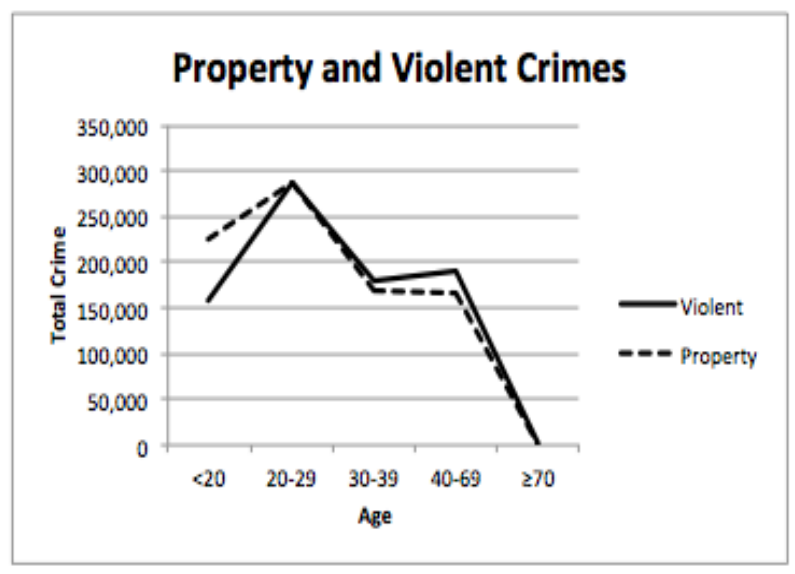

Figure1. depicts the total number of property and violence-related arrests in California between 2007-2013. 
American Research Journal of Humanities and Social Sciences, Volume 1, Issue 4, 2015

ISSN 2378-7031

Visually, the depicted data for property and violent arrests conformed with expectations for a macro perspective. That is, there were no obvious differences in the two trajectories for the different categories of arrests. For the years in question, both property and violent arrest data start out low in the under-20 category, rise and peak in the mid 20's, and decline thereafter; conforming to classic descriptions of the Age-Crime Curve (Hirschi \& Gottfredson, 1983).

These same data are presented in tabular form and the resulting Chi-Square analysis to test for differences in proportionality of distribution across the age categories. The data are presented in both total numbers (in parentheses) and in rounded percentages.

Table1. Chi-Square Analyses of Property and Violent crime across the age categories

\begin{tabular}{|l|l|l|l|l|l|l|}
\hline & $<20$ & $20-29$ & $30-39$ & $40-69$ & $>70$ & Total \\
\hline Property & $26 \%(211,422)$ & $34 \%(285,403)$ & $20 \%(167,735)$ & $20 \%(135,621)$ & $1 \%(1,005)$ & $100 \%(801,186)$ \\
\hline Violence & $20 \%(158,683)$ & $34 \%(286,045)$ & $22 \%(178,698)$ & $23 \%(191,165)$ & $1 \%(2,828)$ & $100 \%(817,419)$ \\
\hline
\end{tabular}

Table1A: Chi-Square analysis of Property and Violent crime, within age categories

\begin{tabular}{|l|l|l|l|l|l|}
\hline & $<20$ & $20-29$ & $30-39$ & $40-69$ & $>70$ \\
\hline Property & $59 \%$ & $50 \%$ & $49 \%$ & $47 \%$ & $27 \%$ \\
& $(211,422)$ & $(285,403)$ & $(167,735)$ & $(135,621)$ & $(1,005)$ \\
\hline Violence & $41 \%$ & $50 \%$ & $51 \%$ & $53 \%$ & $73 \%$ \\
& $(158,683)$ & $(286,045)$ & $(178,698)$ & $(191,165)$ & $(2,828)$ \\
\hline Total & $100 \%$ & $100 \%$ & $100 \%$ & $100 \%$ & $100 \%$ \\
& $(370,105)$ & $(571,448)$ & $(346,433)$ & $(326,786)$ & $(3,833)$ \\
\hline
\end{tabular}

$\chi^{2}=21.78, p<.001, d f=4$

In keeping with the visual impression yielded by Figure 1, the Chi-Square analysis examining the proportion of Property versus Violent arrests across the age categories yielded non-significant findings $\left(\chi^{2}=1.08, \mathrm{p}=.90, \mathrm{df}=4\right)$. Chi-Square analysis of these same figures within age categories also turned up significantly $\left(\chi^{2}=21.78, p<.001\right.$, $\mathrm{df}=4$ ), showing disproportion in the distribution of the crimes. Whereas the breakdown of property versus violent arrest percentages were approximately equal in the first four age categories, arrests for violent offenses made up $73 \%$ of the total for those 70 years of age and older.

The next set of analyses examined specific types of property arrests (burglary, theft, motor vehicle theft and forgery) to see if they differed from one another and the overall ACC. Visually, it is evident that all categories of property crimes except burglary conform to the macro, ACC trajectory; i.e. rise through adolescence, peak in the mid-20's and decline thereafter. Burglary, however, peaks in the years before the age of 20, then declines.

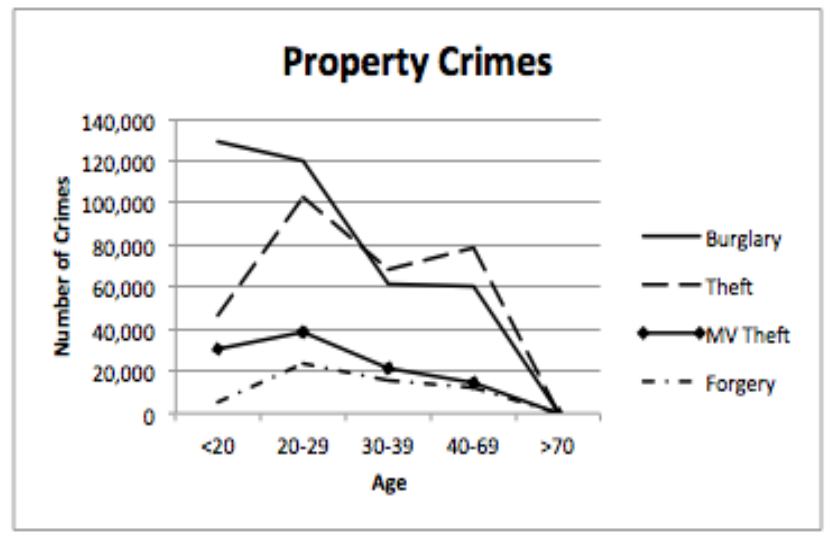

Figure.2

Chi-square analyses of these relationships showed that there were significant differences in specific property and violent crimes distributed across the age brackets, $\left(\chi^{2}=25.88, \mathrm{p}<.001, \mathrm{df}=12\right)$, as well as how these crimes distributed within age brackets $\left(\chi^{2}=34.88, \mathrm{p}<.001, \mathrm{df}=12\right)$. 
American Research Journal of Humanities and Social Sciences, Volume 1, Issue 4, 2015

ISSN 2378-7031

Table2. Chi-Square Analysis of Property crimes, across the age categories.

\begin{tabular}{|l|l|l|l|l|l|l|}
\hline & $<20$ & $20-29$ & $30-39$ & $40-69$ & $>70$ & Total \\
\hline Burglary & $33 \%(129,392)$ & $32 \%(120,265)$ & $17 \%(61,534)$ & $16 \%(59,896)$ & $1 \%(351)$ & $\begin{array}{l}100 \% \\
(371,438)\end{array}$ \\
\hline Theft & $\begin{array}{l}16 \% \\
(46,434)\end{array}$ & $35 \%(102,847)$ & $23 \%(68,310)$ & $26 \%(78,297)$ & $1 \%(536)$ & $\begin{array}{l}100 \% \\
(296,424)\end{array}$ \\
\hline $\begin{array}{l}\text { MV } \\
\text { Theft }\end{array}$ & $\begin{array}{l}29 \% \\
(30,233)\end{array}$ & $\begin{array}{l}37 \% \\
(38,996)\end{array}$ & $20 \%(21,678)$ & $14 \%(14,589)$ & $\begin{array}{l}1 \% \\
(53)\end{array}$ & $\begin{array}{l}100 \% \\
(105,549)\end{array}$ \\
\hline Forgery & $\begin{array}{l}9 \% \\
(5,363)\end{array}$ & $\begin{array}{l}40 \% \\
(23,295)\end{array}$ & $28 \%(16,213)$ & $22 \%(12,729)$ & $\begin{array}{l}1 \% \\
(65)\end{array}$ & $\begin{array}{l}100 \% \\
(57,665)\end{array}$ \\
\hline
\end{tabular}

$\chi^{2}=25.88, p<.001, d f=12$

Table2A. Chi-Square Analyses of Property crimes, within age categories

\begin{tabular}{|c|c|c|c|c|c|}
\hline & $<20$ & $20-29$ & $30-39$ & $40-69$ & $>70$ \\
\hline Burglary & $\begin{array}{l}61 \% \\
(129,392)\end{array}$ & $\begin{array}{l}42 \% \\
(120,265)\end{array}$ & $\begin{array}{l}37 \% \\
(61,534)\end{array}$ & $\begin{array}{l}36 \% \\
(59,896)\end{array}$ & $\begin{array}{l}35 \% \\
(351)\end{array}$ \\
\hline Theft & $\begin{array}{l}22 \% \\
(46,434)\end{array}$ & $\begin{array}{l}36 \% \\
(102,847)\end{array}$ & $\begin{array}{l}41 \% \\
(68,310)\end{array}$ & $\begin{array}{l}47 \% \\
(78,297)\end{array}$ & $\begin{array}{l}53 \% \\
(536)\end{array}$ \\
\hline MV Theft & $\begin{array}{l}14 \% \\
(30,233)\end{array}$ & $\begin{array}{l}14 \% \\
(38,996)\end{array}$ & $\begin{array}{l}13 \% \\
(21,678)\end{array}$ & $\begin{array}{l}9 \% \\
(14,589)\end{array}$ & $\begin{array}{l}5 \% \\
(53)\end{array}$ \\
\hline Forgery & $\begin{array}{l}3 \% \\
(5,363)\end{array}$ & $\begin{array}{l}8 \% \\
(23,295)\end{array}$ & $\begin{array}{l}10 \% \\
(16,213)\end{array}$ & $\begin{array}{l}8 \% \\
(12,729)\end{array}$ & $\begin{array}{l}6 \% \\
(65) \\
\end{array}$ \\
\hline Total & $\begin{array}{l}100 \% \\
(211,422)\end{array}$ & $\begin{array}{l}100 \% \\
(285,403)\end{array}$ & $\begin{array}{l}100 \% \\
(167,735)\end{array}$ & $\begin{array}{l}100 \% \\
(165,511)\end{array}$ & $\begin{array}{l}100 \% \\
(1,005)\end{array}$ \\
\hline
\end{tabular}

$\chi^{2}=34.88, p<.001, d f=12$

Specific violent crimes (homicide, forcible rape, robbery, assault, kidnapping) were examined next, in order to determine if their trajectory across the age brackets differed from one another and the overall ACC. These data are depicted visually in Figure 3.

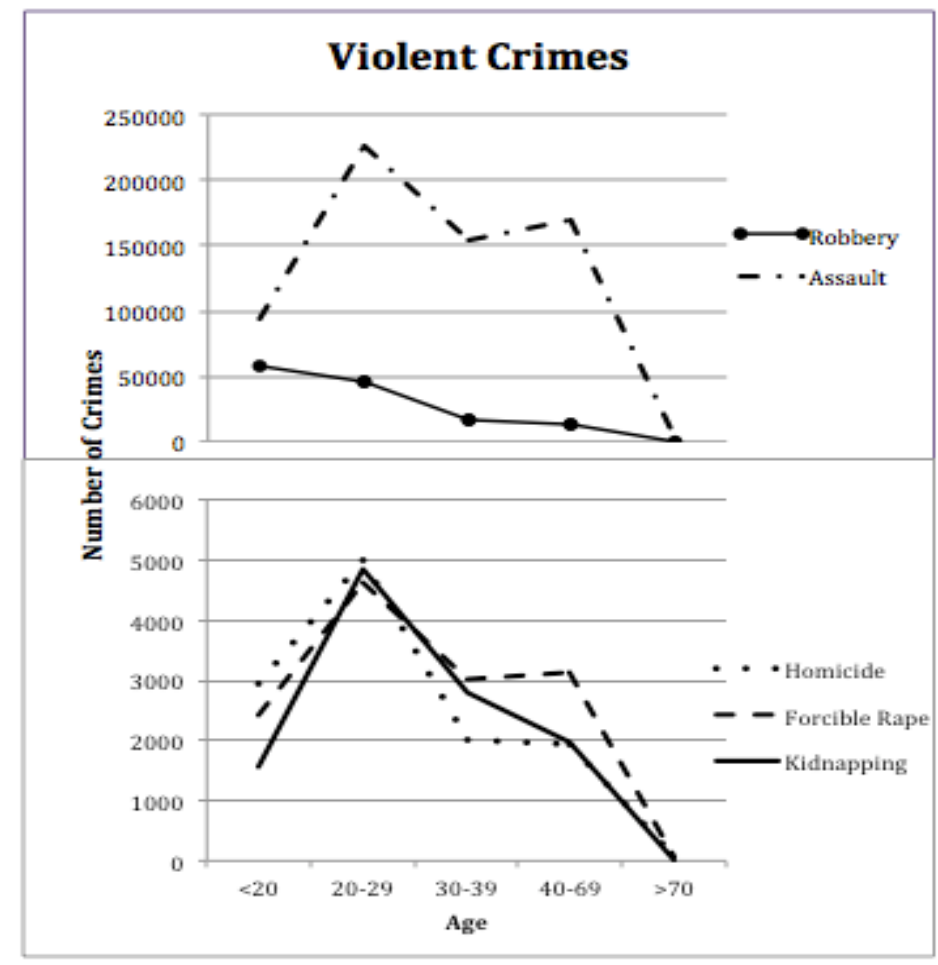

Figure.3 
American Research Journal of Humanities and Social Sciences, Volume 1, Issue 4, 2015

ISSN 2378-7031

The visual depiction of robbery differed from its other violent counterparts. Unlike the other violent crimes which configured in a manner consistent with the overall ACC, robbery arrest rates actually peaks before the age of 20, and declines thereafter. Two separate analyses were conducted to help isolate the effects of burglary and robbery on the trajectories of property and violent arrests, respectively. Without burglary in the analysis, property crimes differed from one another, to a slightly significant level. This resulted in significant differences across $\left(\chi^{2}=41.74, \mathrm{p}<.001\right.$, $\mathrm{df}=16)$ and within age categories $\left(\chi^{2}=63.97, \mathrm{p}<.001, \mathrm{df}=16\right)$.

Table3. Chi-Square analysis Violent crimes across age categories.

\begin{tabular}{|l|l|l|l|l|l|l|}
\hline & $<20$ & $20-29$ & $30-39$ & $40-69$ & $>70$ & Total \\
\hline & $25 \%$ & $42 \%$ & $17 \%$ & $16 \%(1,922)$ & $1 \%$ & $100 \%$ \\
Homicide & $(2,943)$ & $(4,996)$ & $(2,000)$ & & $(80)$ & $(11,941)$ \\
\hline & $18 \%$ & $35 \%$ & $23 \%$ & $24 \%(3,146)$ & $1 \%$ & $100 \%$ \\
Forcible Rape & $(2,444)$ & $(4,632)$ & $(3,035)$ & & $(58)$ & $(13,315)$ \\
\hline & $43 \%$ & $34 \%$ & $12 \%$ & $11 \%(14,199)$ & $1 \%$ & $100 \%$ \\
Robbery & $(58,556)$ & $(45,697)$ & $(16,567)$ & & $(59)$ & $(135,078)$ \\
\hline & $14 \%$ & $35 \%(225,859)$ & $24 \%(154,289)$ & $26 \%(16,987)$ & $1 \%(2,618)$ & $100 \%$ \\
Assault & $(93,205)$ & & & & & $(492,958)$ \\
\hline & $14 \%$ & $43 \%$ & $25 \%$ & $18 \%(1,991)$ & $1 \%$ & $100 \%$ \\
Kidnapping & $(1,555)$ & $(4,861)$ & $(2,807)$ & & $(14)$ & $(11,228)$ \\
\hline
\end{tabular}

$\chi^{2}=41.74, p<.001, d f=16$

Table3A. Chi-Square analysis of Violent crimes across crime type

\begin{tabular}{|l|l|l|l|l|l|}
\hline & $<20$ & $20-29$ & $30-39$ & $40-69$ & $>70$ \\
\hline Homicide & 2 & 2 & 1 & 1 & 3 \\
& $(2,943)$ & $(4,996)$ & $(2,000)$ & $(1,922)$ & $(80)$ \\
\hline Forcible Rape & 2 & 2 & 2 & 2 & 2 \\
& $(2,444)$ & $(4,632)$ & $(3,035)$ & $(3,146)$ & $(58)$ \\
\hline Robbery & 37 & 16 & 9 & 7 & 2 \\
& $(58,556)$ & $(45,697)$ & $(16,567)$ & $(14,199)$ & $(59)$ \\
\hline Assault & 59 & 79 & 86 & 89 & 93 \\
& $(93,205)$ & $(225,859)$ & $(154,289)$ & $(16,987)$ & $(2,618)$ \\
\hline Kidnapping & 1 & 2 & 2 & 1 & 1 \\
& $(1,555)$ & $(4,861)$ & $(2,807)$ & $(1,991)$ & $(14)$ \\
\hline Total & $100(158,703)$ & $100(286,045)$ & $100(178,698)$ & $100(38,2455)$ & 100 \\
& & & & & $(2,829)$ \\
\hline
\end{tabular}

$\chi^{2}=63.97, p<.001, d f=16$

Visually, it appears that the different property crimes plot very similarly to one another and the overall ACC, with the exception of Burglary, which (unlike all other Property crimes) peaks before age 20 and then declines across the age span.

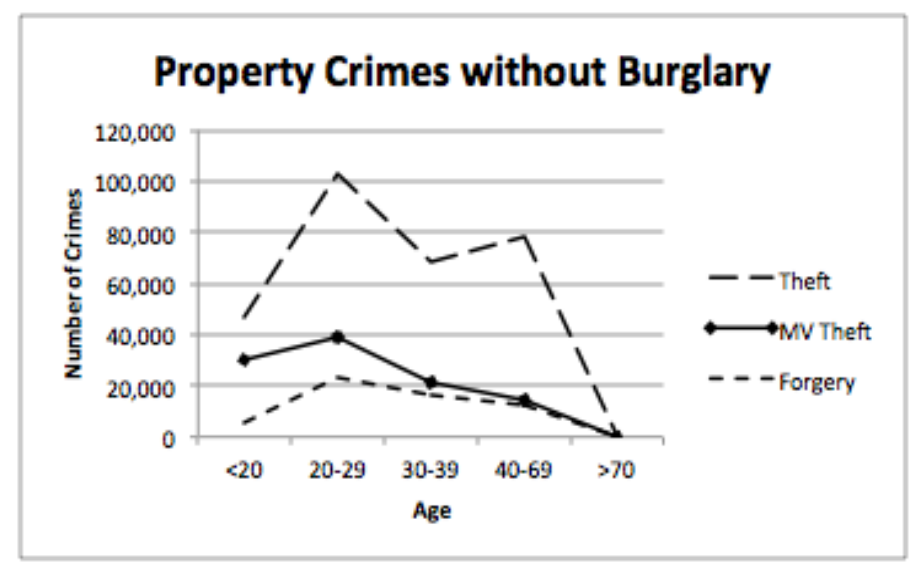

Figure.4 
American Research Journal of Humanities and Social Sciences, Volume 1, Issue 4, 2015

ISSN 2378-7031

A chi-square analysis of these data barely reached significance $\left(\chi^{2}=16.77, \mathrm{p}=.03, \mathrm{df}=8\right)$, and differed substantially from the earlier chi-square that included Burglary.

Table4. Chi-Square analysis of Property crimes, without Burglary.

\begin{tabular}{|l|l|l|l|l|l|l|}
\hline & $<20$ & $20-29$ & $30-39$ & $40-69$ & $>70$ & Total \\
\hline Theft & $\begin{array}{l}16 \\
(46,434)\end{array}$ & $35(102,847)$ & $23(68,310)$ & $26(78,297)$ & 1 & 100 \\
$(536)$ & $(296,424)$ \\
MV Theft & $\begin{array}{l}29 \\
(30,233)\end{array}$ & $37(38,996)$ & $20(21,678)$ & $14(14,589)$ & $\begin{array}{l}1 \\
(53)\end{array}$ & $\begin{array}{l}100 \\
(105,549)\end{array}$ \\
\hline & 9 & $40(23,295)$ & $28(16,213)$ & $22(12,729)$ & 1 & 100 \\
Forgery & $(5,363)$ & & & & $(65)$ & $(57,665)$ \\
\hline
\end{tabular}

$\chi^{2}=16.77, p=.03, d f=8$

A similar approach was taken with violent crimes to help isolate the effect of Robbery on the distribution of all violent crime categories across the age brackets. Robbery also peaked before age 20 and declined thereafter. This is depicted visually on Figure 5.

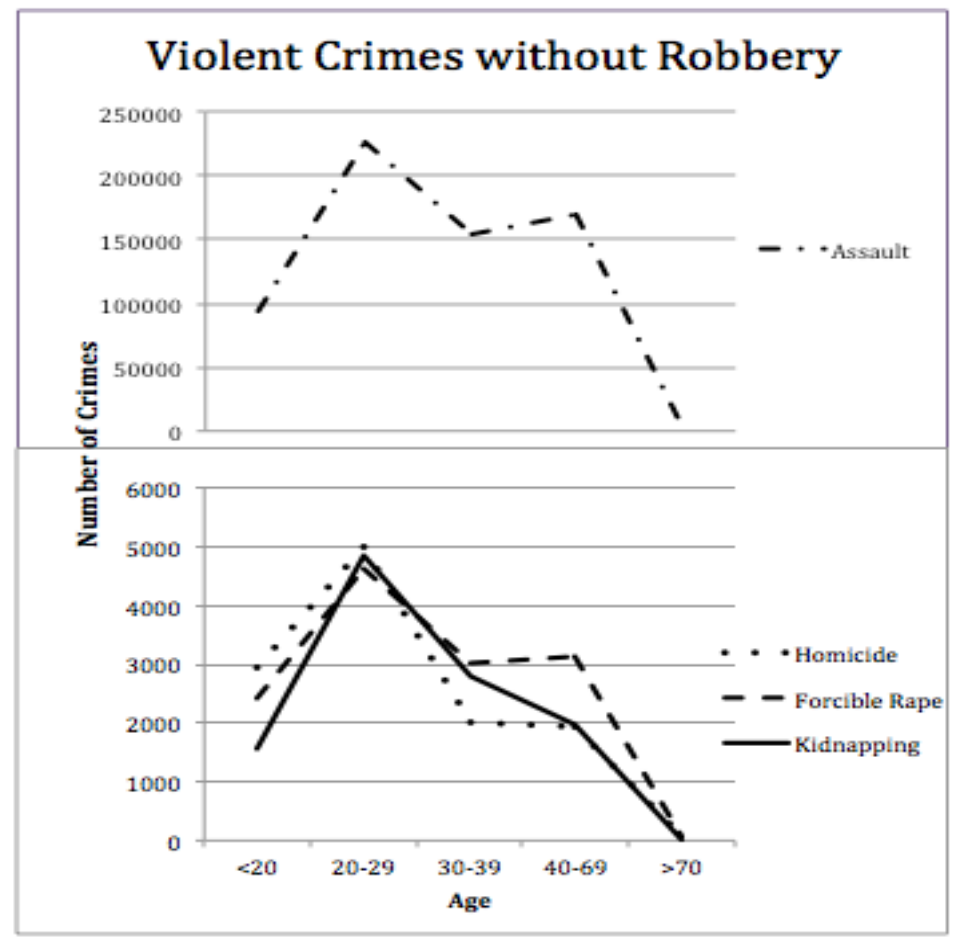

Figure 5.

There were no apparent visual differences in the trajectories of the other four violent crimes without Robbery. A Chi-Square analysis of these data turned up non-significantly different $\left(\chi^{2}=10.98, \mathrm{p}=.53, \mathrm{df}=12\right)$.

Table 5. Chi-Square analysis of Violent crimes, without robbery

\begin{tabular}{|l|l|l|l|l|l|l|}
\hline & $<20$ & $20-29$ & $30-39$ & $40-69$ & $>70$ & Total \\
\hline Homicide & $25(2,943)$ & $\begin{array}{l}42 \\
(4,996)\end{array}$ & $\begin{array}{l}17 \\
(2,000)\end{array}$ & $\begin{array}{l}16 \\
(1,922)\end{array}$ & $\begin{array}{l}1 \\
(80)\end{array}$ & $100(11,941)$ \\
\hline $\begin{array}{l}\text { Forcible } \\
\text { Rape }\end{array}$ & $18(2,444)$ & $\begin{array}{l}35 \\
(4,632)\end{array}$ & $\begin{array}{l}23 \\
(3,035)\end{array}$ & $\begin{array}{l}24 \\
(3,146)\end{array}$ & $\begin{array}{l}1 \\
(58)\end{array}$ & $100(13,315)$ \\
\hline Assault & $14(93,205)$ & $\begin{array}{l}35 \\
(225,859)\end{array}$ & $24(154,289)$ & $26(16,987)$ & $1(2,618)$ & $100(492,958)$ \\
\hline Kidnapping & $14(1,555)$ & $\begin{array}{l}43 \\
(4,861)\end{array}$ & $\begin{array}{l}25 \\
(2,807)\end{array}$ & $\begin{array}{l}18 \\
(1,991)\end{array}$ & $\begin{array}{l}1 \\
(14)\end{array}$ & $100(11,228)$ \\
\hline
\end{tabular}

$\chi^{2}=10.98, p=.53, d f=12$ 


\section{SUMMARY AND DISCUSSION}

The Age Crime Curve (ACC) phenomenon has long been considered one of the more venerable finding in criminology (Sweeten et al., 2013). While initial theoretical models emphasized its invariance and biological roots (Hirschi \& Gottfredson, 1983), more recent investigations have begun articulating differences in the trajectories during different periods of time (Ulmer \& Steffensmeier, 2013), by gender and ethnic groups (Laub \& Sampson, 2003), individual involvement trajectories (Sampson \& Laub, 2013) and types of offenses (McCall, 2013).

The current study followed this line of empirical work by examining arrest rates for various types of Property and violent crimes, across 7 years (2007-2013) of state-wide arrest data compiled by the California State Department of Justice (CSDOJ). We combined arrest data for Burglary, Theft, Motor Vehicle Theft and Forgery (purely crimes of acquisition, without personal confrontations) into the category of property crimes. Similarly, we combined Homicide, Forcible Rape, Robbery, Assault and Kidnapping (crimes of aggression against people), into a category of violent crimes. Our data were grouped into age-brackets consistent with the categorizations offered by the CSDOJ, depicted into figures and analyzed using Chi-Square tests of significance.

Our most fundamental finding was that Property and Violent crimes, in toto, conformed to the classic description of the Age-Crime Curve (ACC). That is, arrest rates for both broad categories of crimes rose from the adolescent years, peaked in the mid 20's and declined gradually thereafter. This lends support to those claiming an invariant pattern regardless of type of crime. Interestingly, rates of arrest for Property and Violent crimes were about equal (hovering around 50-50 within each age category), except for the $>70$ age category, where $73 \%$ of the arrests perpetrated on those individuals resulted from Violent crimes. The numbers of crimes committed by those in that age category are dwarfed by those in any other category (e.g. 3,833 arrests for those 70 and over, versus a nearly one hundred fold greater number, 330,619 for those between 40 and 69 years of age, for example).

Our most provocative set of findings occurred when we examined the trajectories of particular types of Property as well as Violent crimes. Chi-Square analyses showed that Burglary and Robbery showed significantly different trajectories from their Property and Violent counterparts, respectively. Unlike all other Property crime we examined, Burglary arrests actually go down from the $<20$ category to the 20-29 age category. Although not as dramatically steep as Burglary, Robbery also showed a decline from the earliest $(<20)$ to the next category $(20-39)$.

These findings challenge the invariance hypothesis of the ACC. While overall crime rates may well conform to its classic description (as our total arrest rates show), all types of crimes certainly do not conform to this pattern, according to our findings. It would appear that the motivations and incentives at work within the crimes of Burglary and Robbery are most operative within the under 20 cohort of individuals. Both involve what could be considered more visceral, brazen, emotionally-based forms of crime; i.e. going into someone's dwelling in the case of Burglary, and directly confronting someone to steal their belongings in the case of Robbery. As youngsters age, they may turn to less impulsive, emotionally driven forms of crime; such as those making up our other categories.

Prior to the age of 20, youngsters spend a significant amount of time in school, but have time off in the afternoons, when homeowners are less likely to be home. This may well be a factor in the higher rates of Burglary among the younger, school-aged group. As individuals age, and leave school, they may have fewer such opportunities, accounting for the different trajectory shown by Burglary relative to its counterparts.

This study represented some methodological strengths and shortcomings. The sheer number of subjects, representing all the arrests performed in the state of California over a seven year period, speaks to the comprehensiveness of the analysis. The division of Property versus Violent crimes was stark, so the comparison was clearly between crimes of acquisition versus crimes of aggression.

Alternatively, the current study did not investigative all the categories of crimes catalogued by the CSDOJ. It is entirely plausible that other forms of crimes may well represent a trajectory that either conforms to or differs from the ACC. By not analyzing those, we may well have overlooked data that could inform the inquiries to the ACC phenomenon. Future researchers may want to include all forms of arrests in investigating ACC trajectories. It may also be instructive to analyze the data with different categorizations of age, or with no age categorizations at all; examining more nuanced relationships between aging and criminal conduct. 


\section{REFERENCES}

[1] Anderson, C. A., Bushman, B. J., \& Groom, R. W. (1997). Hot years and serious and deadly assault: Empirical tests of the heat hypothesis. Journal Of Personality And Social Psychology, 73(6), 1213-1223.

[2] Andresen, M. A., \& Felson, M. (2012). An investigation into the fundamental regularities of co-offending for violent and property crime classifications. Canadian Journal of Criminology \& Criminal Justice, 54(1), 101-115.

[3] Broidy, L., \& Agnew, R. (1997). Gender and Crime: A general strain theory perspective. In The female offender: Girls, women, and crime (pp. 3-18 Gen). Thousand Oaks: Sage Publications.

[4] Collins, R. E. (2004). Onset and desistance in criminal careers: neurobiology and the age-Crime relationship. Journal of Offender Rehabilitation, 39(3), 1-19.

[5] Cullen, Francis T. \& Pratt, Travis C. (2005). Assessing macro-level predictors and theories of crime: Ameta-analysis. Crime and Justice, 32, 373-450.

[6] Douglas, K. S., Hart, S. D., Webster, C. D., \& Belfrage, H. (2013). HCR-20v3: Assessing risk for violence: User guide. Mental Health, Law, and Policy Institute, Simon Fraser University.

[7] D'Unger, A. V., Land, K. C., \& McCall, P. L. (2002). Sex differences in age patterns of delinquent/criminal careers: Results from Poisson Latent Class Analyses of the Philadelphia Cohort Study. Journal Of Quantitative Criminology, 18(4), 349375

[8] Fabio, A., Tu, L., Loeber, R., \& Cohen, J. (2011). Neighborhood socioeconomic disadvantage and the shape of the agecrime curve. American Journal Of Public Health, 101(Suppl 1), S325-S332.

[9] Fagan, A. A., \& Western, J. (2005). Escalation and deceleration of offending behaviours from adolescence to early adulthood. Australian \& New Zealand Journal of Criminology (Australian Academic Press), 38(1), 59-76.

[10] Farrington, D. P., Ttofi, M. M., \& Coid, J. W. (2009). Development of adolescence-limited, late-onset, and persistent offenders from age 8 to age 48. Aggressive Behavior, 35(2), 150-163.

[11] Flores de Apodaca, R., Brighton, L. M., Perkins, A. N., Jackson, K. N., \& Steege, J. R. (2012). Characteristics of schools in which fatal shootings occur. Psychological Reports, 110(2), 363-377.

[12] Godfrey, E. A., \& Schulman, R. E. (1972). Age and a group test battery as predictors of types of crime. Clinical Psychology, 28(3), 339-342.

[13] Hirschi, T., \& Gottfredson, M. (1983). Age and the Explanation of Crime. American Journal of Sociology, 89(3), 552-584. (1983, January 1). Retrieved August 27, 2014.

[14] Kanazawa, S. \& Still, M.C. (2000) Why men commit crimes (and why they desist). Sociological Theory, 18, 434-447

[15] Kirk, D. S. (2006). Examining the divergence across self-report and official data sources on inferences about the adolescent life-course of crime. Journal of Quantitative Criminology, 22, 107-129.

[16] Laub, J. H. \& Sampson, R. J. (1992). Crime and deviance in the life course. Annual Review of Sociology, 18, 63-84.

[17] Le, T. N., \& Stockdale, G. D. (2011). Influence of generational status on developmental trajectories of delinquency for Asian, African American, Hispanic, and White youth. Asian American Journal Of Psychology, 2(4), 306-315.

[18] Loeber, R., Farrington, D. P., \& Petechuk, D. (2013). Bulletin 1: From juvenile delinquency to [young adult offending (study group on the transitions between juvenile delinquency and adult crime). National Institute of Justice. (1), 1-23.

[19] McCall, P., Land, K., Dollar, C., \& Parker, K. (2013). The age structure-crime rate relationship: Solving a long-standing puzzle. Journal Of Quantitative Criminology, 29(2), 167-190.

[20] Piquero, A. R., Fagan, J., Mulvey, E. P., Steinberg, L., \& Odgers, C. (2005). Developmental Trajectories of Legal Socialization Among Serious Adolescent Offenders. Journal Of Criminal Law \& Criminology, 96(1), 267-298.

[21] Sampson, R. J., \& Laub, J. H. (2003). Life-course Desisters? Trajectories of crime among delinquent boys to age 70. Criminology, 41(3), 555-592.

[22] Sampson, R. J., \& Laub, J. H. (2005). A life-course view of the development of crime. Annals of the American Academy of Political and Social Science, 602, 12-45

[23] Shulman, E. P., Steinberg, L. D., \& Piquero, A. R. (2013). The age-crime curve in adolescence and early adulthood is not due to age differences in economic status. Journal of Youth And Adolescence, 42(6), 848-860.

[24] Steffensmeier, D. \& Streifel C. (1991). Age, gender, and crime across three historical periods: 1935, 1960, and 1985. Social Forces, 69, 869-894

[25] Sweeten G., Piquero, A., \& Steinberg, L. (2013). Age and the explanation of crime, Revisited. Journal of Youth \& Adolescence, 42(6), 921-938.

[26] Tittle, C. R. \& Grasmick, H. G. (1997). Criminal behavior and age: a test of three provocative hypotheses. Journal of Criminal Law \& Criminology 88(7), 309-342. 